\title{
Kalkkunoiden hyvinvointi kuljetuksen aikana
}

\author{
Laura Hänninen $^{1)}$, Anette Wichman ${ }^{1,2)}$, Marianna Norring ${ }^{1)}$, Matti Pastell ${ }^{1,3)}$ ja Anna Valros ${ }^{1}$ \\ ${ }^{1)}$ Eläinten hyvinvoinnin tutkimuskeskus, 00014 Helsingin Yliopisto, etunimi.sukunimi@ helsinki.fi \\ ${ }^{2)}$ SLU, Box 7084, 75007 Uppsala, Ruotsi \\ ${ }^{3)}$ Agroteknologian laitos, 00014 Helsingin Yliopisto
}

\section{Tiivistelmä}

Kalkkunoiden kuljetusolosuhteiden vaikutuksia lintujen kokemuksiin on tutkittu tieteellisesti vähän. Nykyiset määräykset kalkkunoiden kuljetusolosuhteille perustuvat pitkälti kokemusperäiseen tietoon. Kuljetuslaatikon kokonaistilan rajoittaminen saattaa aiheuttaa epämukavuutta ja stressiä, mutta toisaalta rajoitettu tila kuljetuslaatikossa saattaa estää toisten kalkkunoiden nokkimista ja selkään nousemista.

Kahdessa osakokeessa selvitettiin kalkkunoiden käyttäytymistä eri häkkikorkeuksissa. Laboratorio-oloissa tutkittiin, miten häkkikorkeus (kaupalliset häkit $40 \mathrm{~cm}, 55 \mathrm{~cm}$ ja vapaa korkeus $90 \mathrm{~cm}$ ) ja linnun paino (16 kg ja $17 \mathrm{~kg}$ ) vaikuttivat 36 kalkkunakukon käyttäytymiseen testihäkissä kuuden tunnin kokeen aikana. Lintujen makuu- ja seisomisasennot ja kehonhoito rekisteröitiin jatkuvana havainnointina. Kaupallisessa kuljetuksessa selvitettiin lisäksi, miten kuljetuslaatikon korkeus $(40 \mathrm{~cm}$ ja $55 \mathrm{~cm}$ ) vaikutti kalkkunoiden käyttäytymiseen ( $\mathrm{mm}$. lepoasentoihin, aktiivisuuteen ja läähätykseen, toisten päällä istumiseen) teurastamon odotustilassa sekä ruholöydöksiin ja lihan laatuun. Neljältä kalkkunatilalta kuljetettiin kalkkunakukkoja (900/tila) noin tunnin ajan teurastamoon siten, että osa linnuista oli lastattu $40 \mathrm{~cm}$ korkeisiin häkkeihin ja osa $55 \mathrm{~cm}$ korkeisiin häkkeihin, neljä lintua kuhunkin. Lintujen käyttäytymistä havainnoitiin teurastamon odotustilassa oloaikana (1-3 tuntia) laskien joka 20. minuutti kuinka monta lintua häkissä oli eri asennoissa. Aineistosta laskettiin tuntikohtainen keskimääräinen prosenttiosuus kunkin häkin linnuista eri asennoissa. Teurastuksen jälkeen laskettiin linjalla siipivaurioiden ja selkänaarmujen määrä. Lisäksi lihanlaatua mitattiin teurastuksen jälkeen jokaisesta kuljetuksesta kuudelta linnulta kummastakin häkkikoosta. Häkkikoon vaikutus käyttäytymiseen ja teuraslöydöksiin testattiin lineaarisilla sekamalleilla ottaen toistuvat mittaukset huomioon.

Linnut eivät kykene seisomaan jalat ojennettuna $40 \mathrm{~cm}$ korkeissa kuljetushäkeissä ( $0 \%$ ajasta

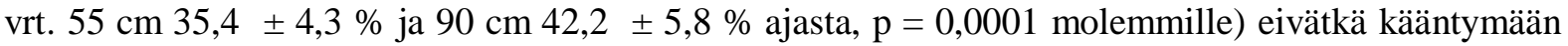
ympäri ( $2 \pm 0,4$ vrt. $55 \mathrm{~cm} 32 \pm 12$ ja $90 \mathrm{~cm} 60 \pm 21$ kertaa, $\mathrm{p}=0,01$ molemmille). Kuuden tunnin testihäkissä oloajan aikana $\mathrm{n} .17 \mathrm{~kg}$ painavat linnut keinahtelivat enemmän puolelta toiselle maatessaan kuin $n$. $16 \mathrm{~kg}$ painavat linnut $(20 \pm 2$ vrt. $26 \pm 3$ kertaa; $p=0,03)$. Linnut läähättävät nokka auki teurastamon odotustilassa enemmän $40 \mathrm{~cm}$ kuin $55 \mathrm{~cm}$ häkeissä $(26,1 \pm 2,4 \%$ vrt. 15,9 $\pm 1,7 \%$ havainnoista, $\mathrm{p}<0,001)$. Toisaalta, $55 \mathrm{~cm}$ korkeissa kuljetushäkeissä on enemmän selkänaarmuja $(20 \pm$ $2,7 \%$ vrt. 5,8 $\pm 1,0 \%$ ruhoista, $\mathrm{p}<0,05)$. Lintujen ei havaittu hyppivän toistensa selkään teurastamon odotustilassa.

Matalat kuljetushäkit estävät lintuja liikkumasta ja seisomasta jalat suorana. Lisäksi linnut läähättävät niissä enemmän teurastamon odotustilassa todennäköisesti kuumuuden ja/tai stressin vuoksi. Korkeammassa kuljetushäkissä linnuilla useimmin esiintyvät selkänaarmut ovat todennäköisesti syntyneet lastauksen tai kuljetuksen aikana. Eri häkkikokojen välillä ei ollut eroja lihanlaadussa. Tulosten perusteella mikään tutkittavista kaupallisessa käytössä olevista kuljetushäkeistä ei osoittautunut olevan optimaalinen lintujen hyvinvointia ajatellen.

Asiasanat: kalkkuna, hyvinvointi, kuljetus 


\section{Johdanto}

Kalkkunoiden kuljetusolosuhteiden vaikutuksia lintujen kokemuksiin on tutkittu tieteellisesti vähän. Nykyiset määräykset kalkkunoiden kuljetusolosuhteille perustuvat pitkälti kokemusperäiseen tietoon (EFSA, 2004). Oletuksenamme oli, että kuljetuslaatikon kokonaistilan rajoittaminen saattaa aiheuttaa epämukavuutta (Wilson ym. 1990, Carlyle ym. 1997) ja stressiä (Heiblum ym. 2000), mutta toisaalta rajoitettu tila kuljetuslaatikossa saattaa estää toisten kalkkunoiden nokkimista ja selkään nousemista. Tässä tutkimuksessa selvitettiin kuljetushäkin korkeuden vaikutusta kalkkunoiden käyttäytymiseen ja fysiologiaan.

\section{Osakoe 1 \\ Aineisto ja menetelmät}

Laboratorio-oloissa selvitettiin miten häkkikorkeus $(40 \mathrm{~cm}, 55 \mathrm{~cm}, 90 \mathrm{~cm})$ ja linnun paino $(18-19 \mathrm{vk}$, n. $16 \mathrm{~kg}$ ja $17 \mathrm{~kg}$ ) vaikuttavat 36 kalkkunakukon (Nicolas 300) käyttäytymiseen vakioiduissa olosuhteissa (eli muut kuljetuksen aikaiset stressorit oli pyritty sulkemaan pois tai vakioimaan). Linnut oli jaettu satunnaisesti kuuden linnun ryhmiin. Yksi ryhmä lintuja testattiin päivässä. Testaus alkoi klo 8:00. Linnut ohjattiin testihäkkiin kuudeksi tunniksi, jonka aikana niiden käyttäytymistä (seisominen, makaaminen, kääntyminen, askeleet, sukiminen) videoitiin. Linnut testattiin kahdesti erikorkuisissa häkeissä $\mathrm{n}$. $10 \mathrm{pv}$ välein. Lisäksi kuusi lintua testattiin vain kerran korkeimmassa häkkikorkeudessa jotta toistomittauksen vaikutus voitiin selvittää.

Häkissä oloajan jälkeen lintujen siipisuonesta otettiin verinäyte $0.8 \mathrm{G}$ neulalla vakuumin avulla 3ml EDTA putkeen. Näytteistä analysoitiin lihas- ja stressihormoneja (kreatiinikinaasi CK, heterofiili-lymfosyytti-suhde H:L, laktaatti ja ASAT).

Häkkikorkeuden vaikutusta lintujen käyttäytymiseen ja fysiologisiin parametreihin analysoitiin sekamallilla, jossa kiinteinä tekijöinä olivat häkkikorkeus ja testikerta, sekä niiden välinen interaktio. Lintu oli mallissa satunnaistekijänä. Mikäli residuaalit eivät olleet normalisti jakautuneita, käytettiin tilastolliseen testaukseen Mann-Whittney - ja Kruskal-Wallis - testejä.

\section{Osakoe 2}

Kaupallisessa kuljetuksessa selvitettiin, miten kuljetuslaatikon korkeus vaikuttaa kalkkunoiden käyttäytymiseen teurastamon odotustilassa, ruholöydöksiin ja lihan laatuun. Neljältä kalkkunatilalta kuljetettiin kalkkunakukkoja noin tunnin ajan teurastamoon siten, että osa linnuista (504 lintua/tila) oli lastattu $40 \mathrm{~cm}$ korkeisiin häkkeihin ja osa (480 lintua/tila) $55 \mathrm{~cm}$ korkeisiin häkkeihin, neljä lintua kuhunkin. Kaikki samalta tilalta kokeeseen osallistuvat linnut kuljetettiin samassa kuljetuksessa. Kuljetushäkit oli tasaisesti sijoitettu autoon.

Lintujen käyttäytymistä (makaaminen, seisominen, läähätys, tappelut) havainnointiin teurastamon odotustilassa olojan (1-3 tuntia). Teurastuksen, ja höyhenten poiston jälkeen lintujen siipivaurioiden ja selkänaarmujen määrä rekisteröitiin. Linnuilla rekisteröitiin olevan selkänaarmu, mikäli naarmu oli vähintään $7 \mathrm{~cm}$ pitkä ja siipivaurio, mikäli siivessä oli joko punainen vähintään $3,75 \mathrm{~cm}^{2}$ ruhje tai avomurtuma. Pyrstövaurioksi rekisteröitiin vähintään $7,5 \mathrm{~cm}^{2}$ kokoinen punainen alue. Lisäksi jokaisesta kuljetuksesta valittiin kuusi keskikokoista teurasruhoa kummastakin häkkikorkeudesta lihan laadun mittaukseen ( $\mathrm{pH}$, glykokeeni, laktaatti, väri).

Tilastollista analyysia varten laskettiin prosentuaalinen osuus, kunkin häkin linnuista, joka ilmensi tutkittavia käyttäytymisiä. Odotustilassa oloaika jaettiin neljään ajanjaksoon; heti laatikoiden autosta purun jälkeen, 10-60 min, 70-120min ja 139-220 min laatikoiden purusta. Aineisto ei noudattanut normaalijakaumaa, joten analyysiin käytettiin Mann-Whittney - ja Kruskal-Wallis - testejä. 


\section{Tulokset}

\section{Osakoe 1}

Käyttäytymisten keskimääräinen esiintyminen prosentteina havainnoidusta ajasta on esitetty taulukossa 1 ja jaksojen keskimääräiset lukumäärät taulukossa 2. Kuuden tunnin häkissä oloajan aikana n. 17 $\mathrm{kg}$ painavat linnut keinahtelivat enemmän puolelta toiselle maatessaan kuin $\mathrm{n} .16 \mathrm{~kg}$ painavat linnut $(20 \pm 2$ vrt. $26 \pm 3$ kertaa; $p=0,03)$.

Taulukko 1 Keskimääräinen aika jonka linnut viettivät kussakin käyttäytymisessä kuuden tunnin häkissä oloajan aikana

\begin{tabular}{llll} 
& $\begin{array}{l}\text { Häkkikorkeus } \\
40 \mathrm{~cm}\end{array}$ & $55 \mathrm{~cm}$ & $90 \mathrm{~cm}$ \\
Käyttäytyminen & & & $42,2 \pm 5,8^{\mathrm{a}}$ \\
\hline seisoo & $\mathrm{n} / \mathrm{a}$ & $35,4 \pm 4,3^{\mathrm{a}}$ & $0,36 \pm 0,27^{\mathrm{b}}$ \\
istuu & $1,6 \pm 0,8^{\mathrm{ab}}$ & $1,08 \pm 0,5^{\mathrm{a}}$ & $0,09 \pm 0,08^{\mathrm{b}}$ \\
matala seisonta-asento & $0,7 \pm 0,2^{\mathrm{a}}$ & $0,3 \pm 0,2^{\mathrm{b}}$ & $56,2 \pm 5,8^{\mathrm{b}}$ \\
makaa rinnan päällä & $93,1 \pm 2,1^{\mathrm{a}}$ & $61,5 \pm 4,2^{\mathrm{b}}$ & $1,2 \pm 0,5^{\mathrm{b}}$ \\
makaa kyljellään & $4,6 \pm 1,8^{\mathrm{a}}$ & $1,8 \pm 0,6^{\mathrm{b}}$ & \\
\hline
\end{tabular}

Eri kirjaimet merkitsevät tilastollisesti merkitsevää $(\mathrm{p}<0,05)$ eroavaisuutta häkkikorkeuksien välillä n/a tarkoittaa, ettei käyttäytymistä havaittu

Taulukko 2 Eri käyttäytymisjaksojen keskimääräinen lukumäärä kuuden tunnin häkissä oloajan aikana

\begin{tabular}{|c|c|c|c|}
\hline Käyttäytyminen & $\begin{array}{l}\text { Häkkikorkeus } \\
40 \mathrm{~cm}\end{array}$ & $55 \mathrm{~cm}$ & $90 \mathrm{~cm}$ \\
\hline Askellus & $0,7 \pm 0,3^{\mathrm{a}}$ & $38,6 \pm 5,8^{b}$ & $59,8 \pm 11,0^{b}$ \\
\hline Kääntyminen & $1,7 \pm 0,4^{\mathrm{a}}$ & $32,3 \pm 12,1^{b}$ & $59,9 \pm 21,0^{\mathrm{b}}$ \\
\hline Seisomaannousuyritys & $15,3 \pm 1,4^{\mathrm{a}}$ & $9,5 \pm 0,9^{\mathrm{b}}$ & $8,8 \pm 0,9^{\mathrm{b}}$ \\
\hline Puolen vaihto maatessa & $32,7 \pm 3,1^{\mathrm{a}}$ & $20,1 \pm 2,3^{\mathrm{b}}$ & $16,1 \pm 2,1^{\mathrm{b}}$ \\
\hline Sukiminen & $5,1 \pm 1,1^{\mathrm{a}}$ & $15,5 \pm 1,6^{\mathrm{b}}$ & $26,4 \pm 3,2^{\mathrm{c}}$ \\
\hline Siiven nosto & $1,0 \pm 0,2$ & $1,6 \pm 0,3$ & $6,1 \pm 1,4$ \\
\hline Venyttely & $\mathrm{n} / \mathrm{a}$ & $0,5 \pm 0,2$ & $2,2 \pm 0,6$ \\
\hline Ravistelu & $\mathrm{n} / \mathrm{a}$ & $0,2 \pm 0,1$ & $0,3 \pm 0,1$ \\
\hline
\end{tabular}

Eri kirjaimet merkitsevät tilastollisesti merkitsevää $(\mathrm{p}<0,05)$ eroavaisuutta häkkikorkeuksien välillä $\mathrm{n} / \mathrm{a}$ tarkoittaa, ettei käyttäytymistä havaittu

Häkkikorkeus ei vaikuttanut keskimääräisiin CK ja ASAT pitoisuuksiin eikä $\mathrm{H}: \mathrm{L}$ suhteeseen., jotka olivat CK $25450 \mathrm{IU} / \mathrm{L} \pm 1733$, ASAT $625 \pm 24 \mathrm{IU} / \mathrm{L}, \mathrm{H}: \mathrm{L}$ suhde $0,98 \pm 0,09$. Häkkikorkeudella oli sen sijaan vaikutus laktaattipitoisuuteen; $55 \mathrm{~cm}$ korkeassa häkissä oli matalampi seerumin laktaattipitoisuus $(2,7 \pm 0,1 \mathrm{mmol} / \mathrm{L})$ kuin $40 \mathrm{~cm}(4,3 \pm 0,7 \mathrm{mmol} / \mathrm{L}, \mathrm{p}=0,001)$ tai $90 \mathrm{~cm}(3,6 \pm 0,4 \mathrm{mmol} / \mathrm{L}, \mathrm{p}=0,05)$ korkeassa kuljetushäkissä. Muihin tutkittuihin parametreihin häkkikoolla ei ollut vaikutusta. Lisäksi CK korreloi positiivisesti lintujen elopainoon ( $\mathrm{r}: 0,57, \mathrm{p}=0,0001)$ ja ASAT pitoisuuden kanssa ( $\mathrm{r}$ : $0,81, \mathrm{p}=0,0001)$.

\section{Osakoe 2}

Linnut läähättävät nokka auki teurastamon odotustilassa enemmän $40 \mathrm{~cm}$ kuin $55 \mathrm{~cm}$ häkeissä $(26,1 \pm$ $2,4 \%$ vrt. $15,9 \pm 1,7 \%$ havainnoista, $\mathrm{p}<0,001)$. Suurempi osa $40 \mathrm{~cm}$ korkeassa häkissä pidetyistä linnuista makasi odotustilassa kuin $55 \mathrm{~cm}$ häkissä olevista linnuista $(96,7 \pm 0,7 \%$ vs. 82,6 $\pm 1,4 \%$, $\mathrm{p}=0.0001$ ). Suorin jaloin seisomista ei ollut $40 \mathrm{~cm}$ korkeassa häkissä ja $55 \mathrm{~cm}$ korkeassa häkissä havaittiin keskimäärin 13,4 $\pm 1,2 \%$ linnuista. Häkkikorkeudella ei ollut vaikutusta istumisen (lintu rinta ylhäällä ja jompikumpi tai molemmat kintereet maassa) ja matalan seisoma-asennon (linnulla rinta ylhäällä ja kintereet irti maasta, mutta jalat eivät ole suoraksi ojentuneet) esiintymiseen. Odotustilassa oloaika vaikutti makaavien ja istuvien lintujen osuuteen ( $\mathrm{p}=0,0001): 55 \mathrm{~cm}$ korkeassa häkissä pidetyt linnut seisoivat enemmän heti saapumisen jälkeen. 
$55 \mathrm{~cm}$ korkeassa kuljetushäkissä oli enemmän selkänaarmuja kuin $40 \mathrm{~cm}$ korkeassa häkissä, muiden vammojen esiintymiseen tai lihan laatuun ei häkkikorkeudella ollut vaikutusta (kuva 1).

Kuva 1. Teurastamon odotustilassaoloajan ja kuljetushäkkikorkeuden vaikutus kalkkunoiden käyttäytymiseen. Havintointervallit: 1: heti laatikoiden autosta purun jälkeen, 2: 10-69 min, 3: 70-129min ja 4: 130-220 min laatikoiden purusta

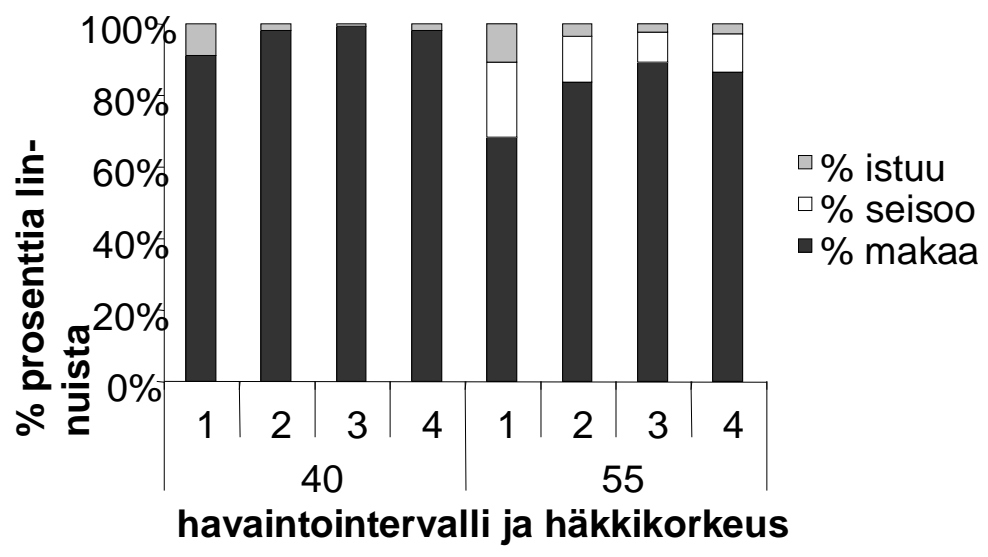

\section{Tulosten tarkastelu}

Kalkkunakukot eivät kyenneet nousemaan ylös $40 \mathrm{~cm}$ korkeissa kuljetushäkeissä, joka vähensi lintujen mahdollisuutta kääntyä ympäri, askeltaa ja sukia höyhenpeitettä. Toisaalta, $55 \mathrm{~cm}$ korkeissa kuljetushäkeissä oli enemmän selkänaarmuja. Naarmut ovat todennäköisesti aiheutuneet lastaus- ja kuljetusaikana toisten lintujen kynsistä. Teurastamon odotustilassa korkeammat kuljetushäkit vähensivät lintujen läähätystä ja lisäsivät niiden liikuntamahdollisuuksia.

Painavimmilla linnuilla on myös suurempi seerumin CK aktiivisuus, joka todennäköisesti on merkki nopean kasvun aiheuttamasta lihassolutuhosta. Suuri CK aktiivisuus myös korreloi positiivisesti kohonneen pehmytkudostuhosta kertovan ASAT pitoisuuden kanssa, mikä osaltaan vahvistaa kudostuhoepäilyä (Broom, 2000).. Myös aiemmissa tutkimuksissa on havaittu vastaavaa (Hocking et al., 1998, Wilson et al., 1990). Ihmisillä liikunnan aiheuttama lihastuho kuvataan kivuliaaksi (Skurvydas et al., 2006), ja seerumin korkean CK:n mahdollista kivuliaisuutta linnuille selvitetään paraikaa (M. Ylä-Ajos ym. SMT 2010). Seerumin CK ja ASAT korreloivat positiivisesti. ASAT on voi olla merkki pehmytkudostuhosta, ja siten myös lihastuhosta.

Veren laktaattipitoisuus oli matalin $55 \mathrm{~cm}$ korkeassa häkissä pidetyillä linnuilla. Laktaattipitoisuutta on saattanut kohottaa lintujen pakotettu paikoillaan olo $40 \mathrm{~cm}$ korkeassa häkissä, missä ne eivät päässeet kääntymään ympäri. $90 \mathrm{~cm}$ korkeassa häkissä pidettyjen lintujen kohonneet laktaattipitoisuudet saattavat olla seurausta lintujen suuremmasta liikunnallisesta aktiivisuudesta. Kuudentunnin häkissä olon jälkeen keskimääräiset laktaattipitoisuudet olivat molemmissa laktaattipitoisuutta kohottaneissa häkkikorkeuksissa lähellä $4 \mathrm{mmol} / \mathrm{L}$ limit, minkä on usein sanottu olevan ns. anaerobitoimminnan aloittamisen pitoisuus (Stegmann and Kindermann, 1982).

Tutkimuksen mukaan kumpikaan yleisesti käytössä oleva häkkityyppi ei ole ongelmaton. Tulevaisuudessa tulisi kehittää uusia, innovatiivisia kuljetustapoja. Jatkotutkimuksen aihe olisi myös, missä vaiheessa kuljetusta linnuille syntyy ruhjeita, ja voisiko niitä estää muuten kuin rajoittamalla liikkumista eli matalammalla häkillä. Kaikkiaan tutkimuksen tulokset osoittavat, että eläinten hyvinvoinnin kannalta olisi tärkeä tunnistaa kriittiset kuljetuksen vaiheet ja pyrkiä parantamaan niitä. 


\section{Kirjallisuus}

Broom, D.M., 2000. Welfare assessment and problem areas during handling and transport. teoksessa Grandin, T. (Ed), Livestock handling and transport. Cabi publishing, UK, 43-61.

Carlyle, W.W.H., Guise, H.J. \& Cook, P. 1997. Effect of time between farm loading and processing on carcase quality of broiler chickens. Veterinary Record 141: 364

European Food Safety Authority, 2004. The welfare of animals during transport. Scientific report (Question $\mathrm{N}^{\circ}$ EFSA-Q-2003-094)

Heiblum, R., Arnon, E., Gvaryahu, G., Robinson, B. \& Snapir, N., 2000. Short-term stress increases testosterone secretion from testes in male domestic fowl. General Comparative Endocrinology 120: 55-66.

Hocking, P.M., Mitchell, M.A., Bernard, R. \& Sandercock, D.A., 1998. Interaction ofage, strain, sex and food restriction on plasma creatine kinase activity in turkeys. Br. Poult. Sci. 39:360-364.

Stegmann, H. \& Kindermann, W., 1982. Comparison of prolonged exercise tests at the individual anaerobic threshold and the fixed anaerobic threshold of 4 mmol.L(-1) lactate. Int. J. Sports Med. 3:105-110. Skurvydas, A., Sipaviciene, S., Krutulyte, G., Gailiuniene, A., Stasilus, A., Gediminas, M. \& Stanislovaitis, A., 2006. Dynamics of indirect symptoms of skeletal muscle damage after stretch-shortening exercise. Journal of Electromyography and Kinesiology, 16: 629-636.

Wilson, B.W., Nieberg, P.S., Buhr, J.R., Kelly, B.J. \& Shultz, F.T. 1990. Turkey muscle growth and focal myopathy. Poultrty Science 69: 1553-1562. 